\title{
Notes on the vocalizations of Tropical Mockingbird (Mimus gilvus)
}

Peter Boesman

In the following we briefly analyze and compare voice of the different races of Tropical Mockingbird (Mimus gilvus). We also try to quantify the extent of any vocal differences using the criteria proposed by Tobias et al. (2010), as a support for taxonomic review. We have made use of sound recordings available on-line from Xeno Canto (XC).

Our main interest is to analyze song of races magnirostris and antelius, which have been suggested to possibly represent distinct species (HBW Alive, Cody 2016).

There are only a few examples available of song of birds on San Andres (magnirostris):

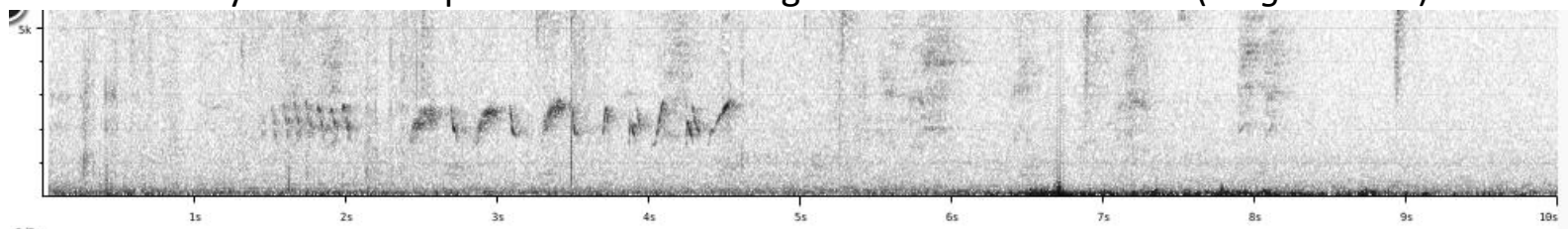

to be compared with e.g.

Honduras

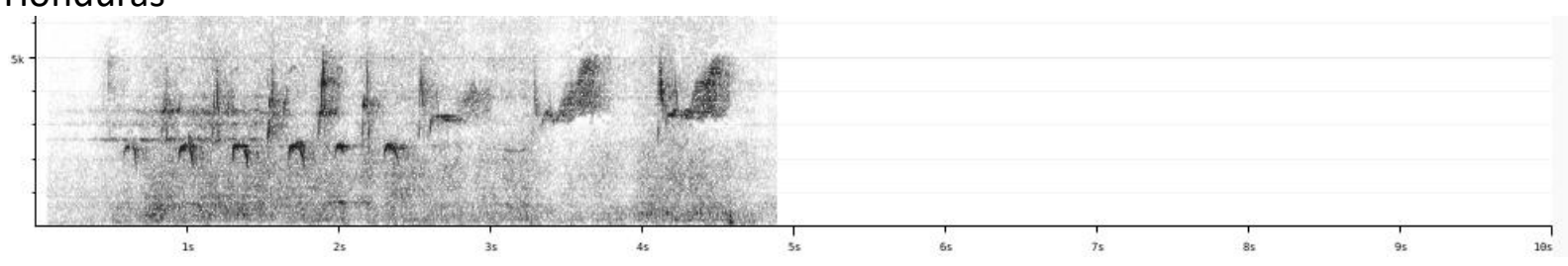

Colombia

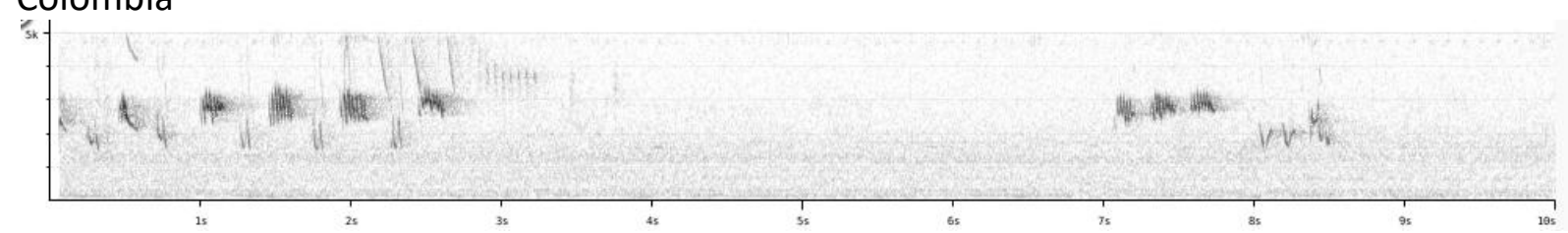

An exact match couldn't be found, but given the extreme variability of songs, the recording of San Andres falls well within the range of vocalizations from the mainland.

More recordings are available of Brazilian race antelius. Some examples:

E Brazil

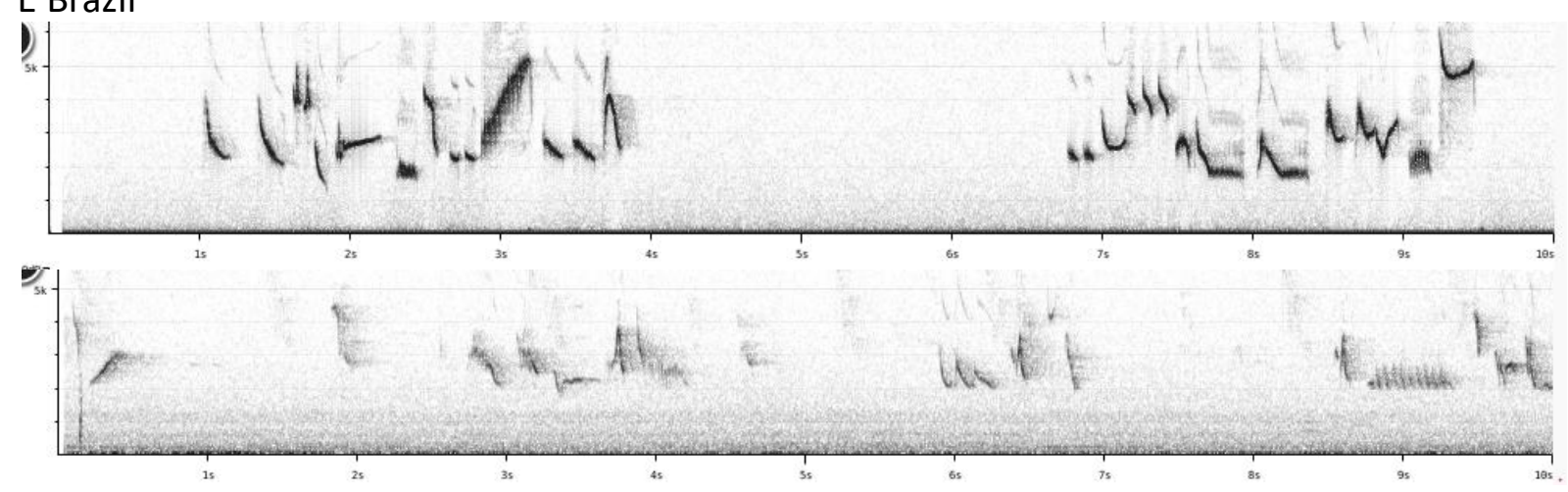


NE Brazil

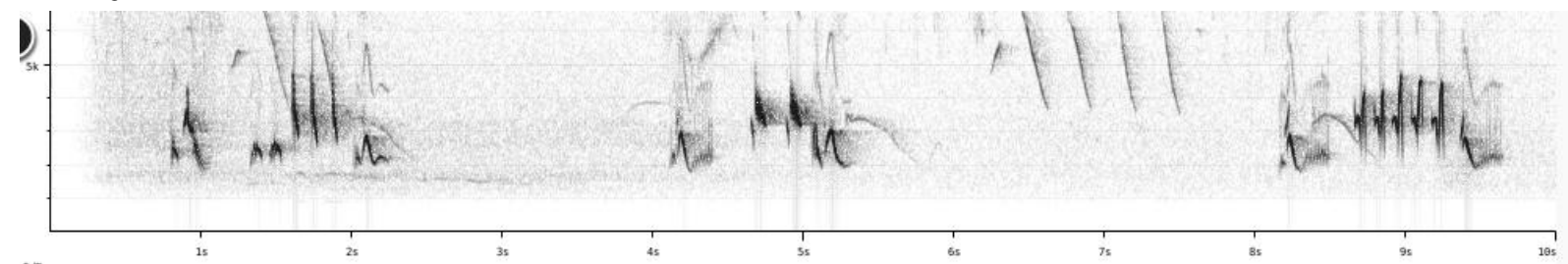

to be compared with e.g.

Venezuela

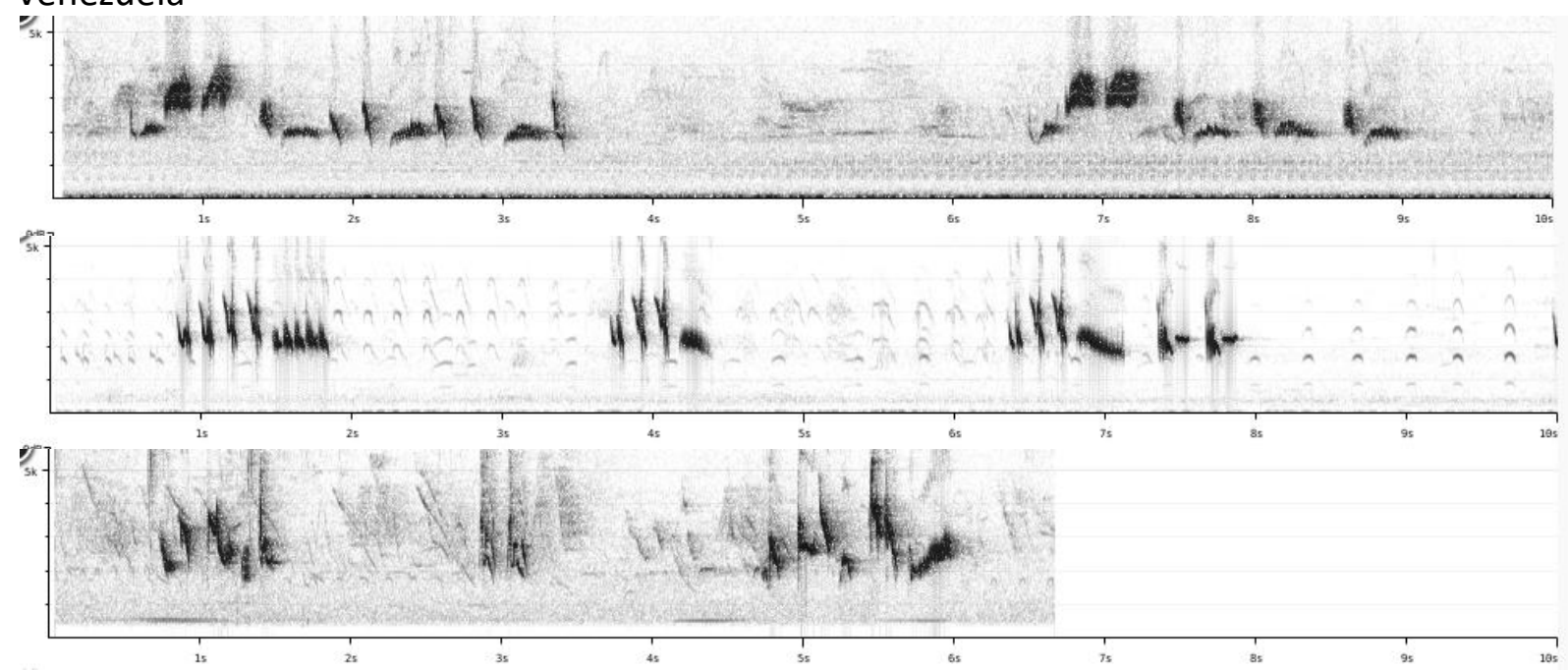

Colombia

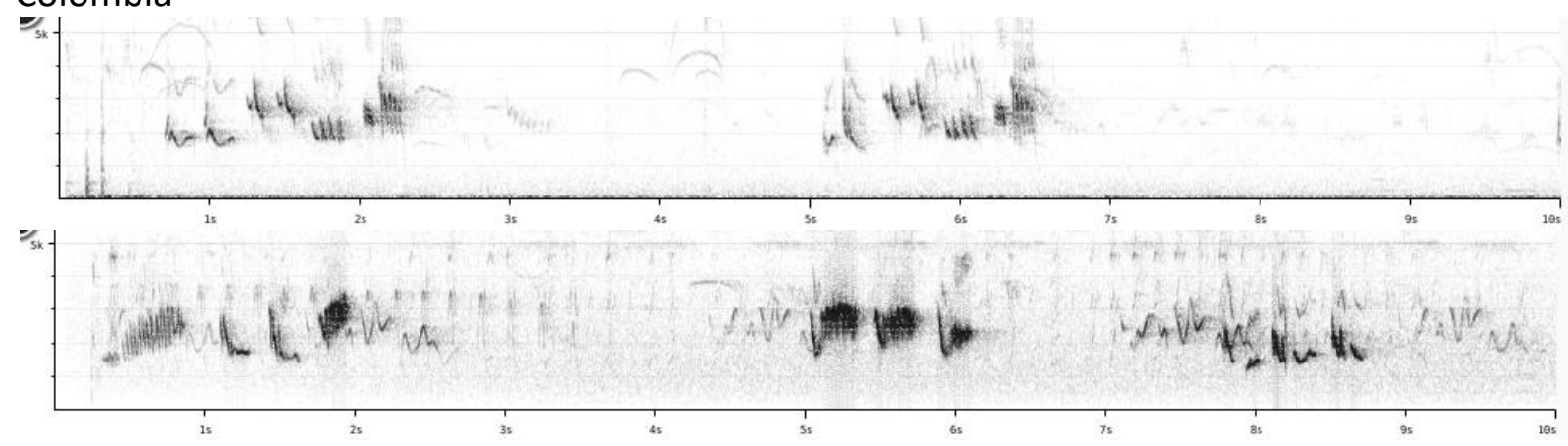

Mexico

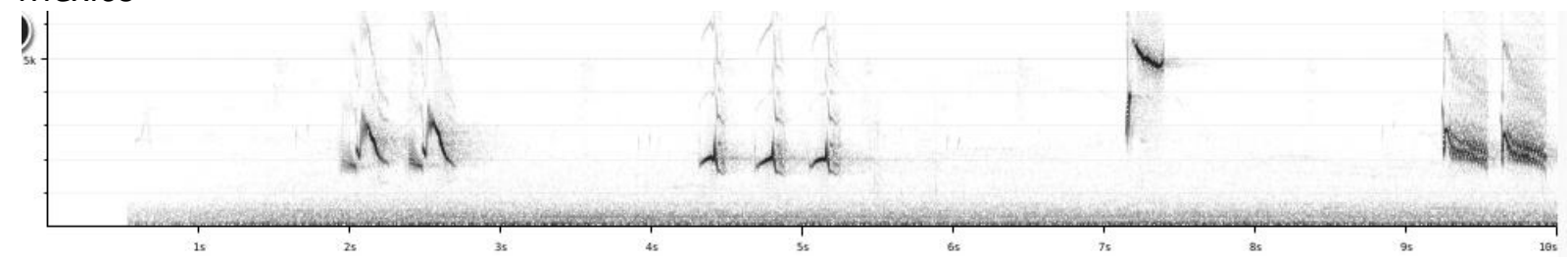

Birds of NE and E Brazil seem to be vocally slightly different. Song is on average slightly higher-pitched, making more use of down-slurred notes and less of burry notes. There is however a lot of variation, and more recordings of Brazil would be needed to confirm this apparent difference.

In any case, difference is rather minor, and we estimate that quantification of vocal differences would lead to a total score of about 1-2. 
This note was finalized on 18th April 2016, using sound recordings available on-line at that moment. We would like to thank in particular the many sound recordists who placed their recordings for this species on XC.

\section{References}

Cody, M. (2016). Tropical Mockingbird (Mimus gilvus). In: del Hoyo, J., Elliott, A., Sargatal, J., Christie, D.A. \& de Juana, E. (eds.). Handbook of the Birds of the World Alive. Lynx Edicions, Barcelona. (retrieved from http://www.hbw.com/node/58187 on 18 April 2016).

Tobias, J.A., Seddon, N., Spottiswoode, C.N., Pilgrim, J.D., Fishpool, L.D.C. \& Collar, N.J. (2010). Quantitative criteria for species delimitation. Ibis 152(4): 724-746.

\section{Recommended citation}

Boesman, P. (2016). Notes on the vocalizations of Tropical Mockingbird (Mimus gilvus). HBW Alive Ornithological Note 298. In: Handbook of the Birds of the World Alive. Lynx Edicions, Barcelona. (retrieved from http://www.hbw.com/node/1251748 on 13 October 2016). 